\title{
Additive Manufacturing Using Melt Extruded Thermoplastics for Tissue Engineering
}

Citation for published version (APA):

Calore, A. R., Sinha, R., Harings, J., Bernaerts, K. V., Mota, C., \& Moroni, L. (2021). Additive

Manufacturing Using Melt Extruded Thermoplastics for Tissue Engineering. In A. Rainer, \& L. Moroni (Eds.), Computer-Aided Tissue Engineering: Methods and Protocols (Vol. 2147, pp. 75-99). Humana. Methods in Molecular Biology https://doi.org/10.1007/978-1-0716-0611-7_7

Document status and date:

Published: 01/01/2021

DOI:

10.1007/978-1-0716-0611-7_7

Document Version:

Publisher's PDF, also known as Version of record

Document license:

Taverne

Please check the document version of this publication:

- A submitted manuscript is the version of the article upon submission and before peer-review. There can be important differences between the submitted version and the official published version of record.

People interested in the research are advised to contact the author for the final version of the publication, or visit the DOI to the publisher's website.

- The final author version and the galley proof are versions of the publication after peer review.

- The final published version features the final layout of the paper including the volume, issue and page numbers.

Link to publication

\footnotetext{
General rights rights.

- You may freely distribute the URL identifying the publication in the public portal. please follow below link for the End User Agreement:

www.umlib.nl/taverne-license

Take down policy

If you believe that this document breaches copyright please contact us at:

repository@maastrichtuniversity.nl

providing details and we will investigate your claim.
}

Copyright and moral rights for the publications made accessible in the public portal are retained by the authors and/or other copyright owners and it is a condition of accessing publications that users recognise and abide by the legal requirements associated with these

- Users may download and print one copy of any publication from the public portal for the purpose of private study or research.

- You may not further distribute the material or use it for any profit-making activity or commercial gain

If the publication is distributed under the terms of Article $25 \mathrm{fa}$ of the Dutch Copyright Act, indicated by the "Taverne" license above, 


\title{
Chapter 7
}

\section{Additive Manufacturing Using Melt Extruded Thermoplastics for Tissue Engineering}

\author{
Andrea Roberto Calore, Ravi Sinha, Jules Harings, \\ Katrien V. Bernaerts, Carlos Mota, and Lorenzo Moroni
}

\begin{abstract}
Melt extrusion of thermoplastic materials is an important technique for fabricating tissue engineering scaffolds by additive manufacturing methods. Scaffold manufacturing is commonly achieved by one of the following extrusion-based techniques: fused deposition modelling (FDM), 3D-fiber deposition (3DF), and bioextrusion. FDM needs the input material to be strictly in the form of a filament, whereas 3DF and bioextrusion can be used to process input material in several forms, such as pellets or powder. This chapter outlines a common workflow for all these methods, going from the material to a scaffold, while highlighting the special requirements of particular methods. A few ways of characterizing the scaffolds are also briefly described.
\end{abstract}

Key words Tissue engineering, Scaffolds, 3D printing, Fused deposition modelling, Bioextrusion, 3D-fiber deposition, Biofabrication

\section{Introduction}

Additive manufacturing (AM) is a group of well-established techniques in industry to rapidly manufacture objects in a layer-by-layer manner where each individual layer is also created progressively, adding material rather than removing it. Since the last three decades, it has been applied in tissue engineering (TE) to manufacture scaffolds with very complex shapes, thanks to its high degree of control on architectural parameters such as pore size, pore shape, and porosity $[1,2]$.

Depending on the material to be processed and on the processing method itself (which are highly interrelated), several AM techniques have been developed over the last decades. A possible

Electronic supplementary material: The online version of this chapter (https://doi.org/10.1007/978-1-07160611-7_7) contains supplementary material, which is available to authorized users.

Alberto Rainer and Lorenzo Moroni (eds.), Computer-Aided Tissue Engineering: Methods and Protocols, Methods in Molecular Biology, vol. 2147, https://doi.org/10.1007/978-1-0716-0611-7_7,

(C) Springer Science+Business Media, LLC, part of Springer Nature 2021 


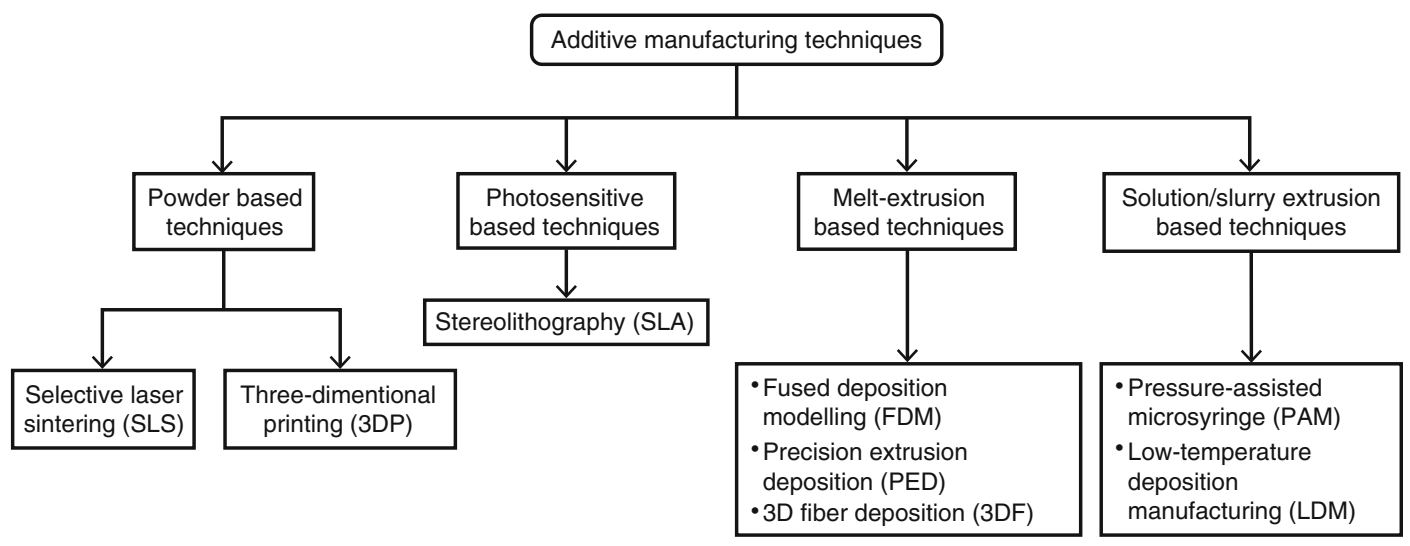

Fig. 1 Proposed classification of the AM techniques commonly employed in TE (adapted from [2])

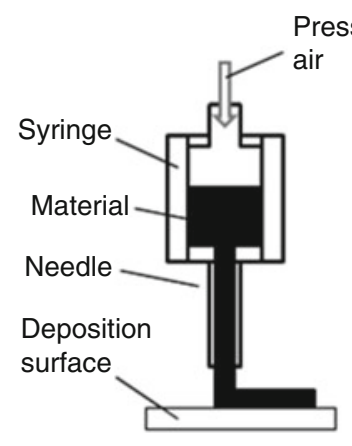

a

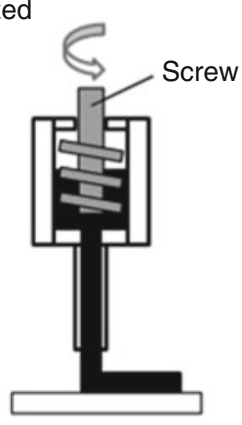

b

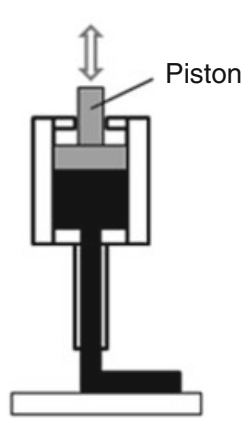

C

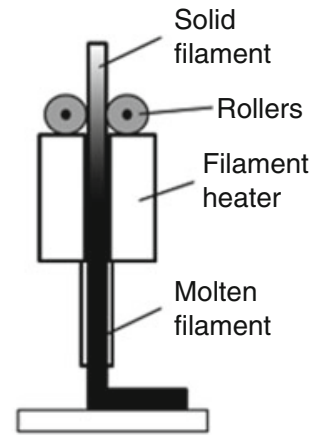

d

Fig. 2 Schematic of fluid dispensing approaches, (a) gas pressure, (b) rotary screw, (c) positive displacement, and (d) roller-assisted (readapted from [3]). In the first three techniques, the material is melted and then extruded by means of pressurized gas (a), a screw (b), or a piston (c). In (d), a solid filament, as it is pushed through a heater (also known as liquefier) by rollers, is melted and can be deposited on the deposition surface

classification is shown in Fig. 1. Selective laser sintering (SLS) uses a laser to selectively sinter powdered material on a heated bed rendering the processing of metals, ceramics, and polymers. Stereolithography (SLA) works by selectively photopolymerizing layers of a photosensitive polymer by means of an ultraviolet (UV) light or laser; both metals and polymers are used. Three-dimensional printing (3DP) is based on the controlled deposition of a binder material laid on a powder layer using an inkjet head, and it is used with polymers. In extrusion-based techniques, the material is made to flow through a nozzle upon the application of pressure via pressurized gas/piston (as shown in Fig. 2a, c), via a screw (Fig. 2b), or via rollers pushing a filament (that acts as a piston, Fig. $2 \mathrm{~d}$ ). The input material is either in molten state (particularly for polymers) or in a slurry form (polymers in solution or hydrogels). The group of 
techniques based on molten materials is usually referred to as fused deposition modelling (FDM) even though this is the name of the filament-based approach [2,4]. As different technologies, still based on melt extrusion, were developed over time, a new nomenclature was recently suggested. In particular, the pressurized gas/ piston-based approach is now being referred to as 3D-fiber deposition, while bioextrusion is used for screw-driven processes [5].

Although each approach has its own advantages, the type of material that can be used with a particular technique is limited by the manufacturing process. For example, FDM and SLS require polymers that become moldable above a specific temperature and solidify upon cooling (called thermoplastics), SLA requires the use of a photopolymer resin, and 3DP involves the use of solvents and binders $[6,7]$.

Tissue engineers have focused their attention on AM techniques attracted by the possibility of controlling the geometry of the scaffold, an essential parameter to be considered when mimicking a tissue's morphology and mechanical properties. Principles and materials typically used in industry have been adapted to the stricter requirements of tissue engineering, mainly due to biocompatibility, but also to the different product morphologies involved, less dense and with a high level of porosity.

Although the first machines developed starting from the $1950 \mathrm{~s}$ were based on SLA, FDM techniques are probably the most successful ones due to their simplicity and low demands on hardware, which makes low-cost printers possible [8]. This applies to the field of tissue engineering in particular, where the high costs of medical grade materials and of the process toward clinical application are pushing research groups to use extrusion-based machines. With the only theoretical requirement for the material to be extrudable, the devices are usually simpler and the operational risks lower compared to SLA, SLS, and 3D printing. This is due to the fact that, generally, no toxic precursors or binders are needed during the shaping process. Additionally, when working with polymers as for hard tissue engineering (e.g., bone and cartilage), melt-based techniques are preferred to solution-based extrusion as they do not involve any solvent that might be toxic for cells. As the polymer cools down and solidifies after extrusion, its stiffness and mechanical strength are high enough so that no curing/gelation step is needed (usually needed with hydrogels). The polymer also retains the given shape as no solvent evaporates.

In tissue engineering, extrusion techniques have been successfully used to produce scaffolds made of hydrogels as well as thermoplastic polymers. The use of hydrogels allows the user to avoid solvents or high temperatures for the extrusion, thanks to their viscoelastic behavior. Therefore, tissue engineers have started embedding cells in the material to be extruded to avoid the further step of cell seeding. Additionally, a better controlled spatial 
distribution of cells can be achieved. Soft tissues such as skin or muscle have been engineered by using hydrogels [9].

On the other hand, the regeneration of stiffer tissues, such as bone and cartilage, has been investigated through the extrusion of thermoplastic polymers. This class of materials naturally offers higher mechanical properties compared to hydrogels, even though the biological cues and the affinity for cells are more limited. To extrude thermoplastics, either solvents or high temperatures are needed, and thus cells cannot be included directly into the printing process. Nevertheless, the mechanical properties have been shown to be suitable for the regeneration of stiff tissues such as cartilage and bone. In particular, it was reported that cartilage mechanical properties could be successfully mimicked by adjusting the fiber deposition pattern of a molten polymer with a pressure-based printer $[10,11]$. The same machine was used to produce also composite scaffolds made of a thermoplastic polymer and hydroxyapatite for bone tissue regeneration [12]. Fibroblasts were successfully cultured on scaffolds made of a thermoplastic polymer/ composite material with a filament-based machine [13]. Recently, a scaffold platform that can actively boost vascularization and may be applied for extrahepatic islet transplantation was manufactured with a thermoplastic polymer deposited with a screw-based extrusion machine [14]. The same approach was used to fabricate scaffolds with an in-built radial interconnected porosity gradient, and cell differentiation assays confirmed the differentiation of hMSCs toward the osteogenic lineage [15].

Considering the huge potential of extrusion-based printing shown in literature, here we demonstrate that scaffolds with the desired geometry, filament diameter, and filament orientation can be successfully produced by means of the three different approaches. We show how to determine the right printing parameters for each technique according to the material properties, and we discuss about the advantages and drawbacks of each approach to be considered before printing.

\section{Materials}

1. PolyActive 300PEOT55PBT45 (molecular weight of the initial PEG used for copolymerization, $300 \mathrm{~g} / \mathrm{mol}$; block weight ratio PEOT/PBT, 55/45). The material is kept stored in a dark and dry place in vacuum-sealed bags prior to use to avoid contamination and moisture absorption.

2. Differential scanning calorimetry (DSC) pans.

3. Microbalance.

4. DSC apparatus. 
5. Rheometer.

6. Computer equipped with CAD software.

7. Mini extruder equipped with $1.5 \mathrm{~mm}$ die.

8. Pushing rod.

9. Aluminum foil.

10. Vacuum bags.

11. Vacuum sealer.

12. Fused deposition modelling apparatus and relative controlling and slicing softwares.

13. 3D-fiber deposition apparatus and relative controlling and slicing softwares.

14. Bioextrusion apparatus and relative controlling and slicing softwares.

15. Double-sided tape.

16. $70 \%$ ethanol

17. SEM sample holders and carbon conductive tape.

18. Liquid nitrogen.

19. Razor blade.

20. SEM apparatus.

21. Sputter coater apparatus (including argon and gold reservoirs).

\section{Methods}

\subsection{Material Characterization}

3.1.1 DSC
The methods described below apply to all three formats of thermoplastic printing, namely, fused deposition modelling (FDM), 3D-fiber deposition (3DF), and bioextrusion, unless differently specified. First, the thermal transitions of the material were analyzed via DSC to determine the temperature region where the polymer is in molten state and can therefore be processed. Then rheometry was used to simulate the flow behavior during printing and to understand the polymer response to processing conditions.

Insights about the thermal and rheological properties of a thermoplastic material are very useful for determining its processing conditions. Two material characterization tests that provide such useful insights are differential scanning calorimetry (DSC) and rheometry.

The DSC measurements described here were run under nitrogen atmosphere and by using a hermetically sealed empty aluminum pan as a reference. The resulting plot for 300PEOT55PBT45 is shown in Fig. 11. To increase the accuracy of the measurements, see Notes 1-3: 


\subsubsection{Rheometry}

1. Find the combined weight of one aluminum pan and one hermetic lid.

2. Cut one pellet of material into a slice of around $5 \mathrm{mg}$, weigh it, and place it inside the pan with the cross section lying on the bottom.

3. Seal the pan with the hermetic lid and load the pan in the DSC apparatus.

4. Program the software to measure the sample according to the following procedure:

(a) Equilibrate the sample temperature at $25^{\circ} \mathrm{C}$.

(b) Heat up to $195{ }^{\circ} \mathrm{C}$ at a rate of $10{ }^{\circ} \mathrm{C} / \mathrm{min}$. The final temperature of the heating cycle should be chosen considering the issues explained in Note 4.

(c) Keep the material isothermally for $3 \mathrm{~min}$ and then cool to $25^{\circ} \mathrm{C}$ at the same rate. A second heating cycle might be needed as described in Note $\mathbf{5}$.

Rheometry measurements were run under nitrogen atmosphere and using a $25 \mathrm{~mm}$ plate-plate geometry. The results are shown in Figs. 12 and 13:

1. Set the temperature of the oven at $200{ }^{\circ} \mathrm{C}$ and allow it to stabilize.

2. Calibrate the gap and load some material on the bottom plate. This step should be carried out taking into account the precautions described in Note 6.

3. Allow the temperature to stabilize again and then close the plates to the measuring gap. Trim the extra material and lower the gap by an additional $15 \mu \mathrm{m}$ to get a proper meniscus. Consider the recommendations in Notes 7 and $\mathbf{8}$ for proper gap adjusting.

4. Start the measurement according to the following protocol:

(a) Time sweeps at $1 \%$ strain, $1 \mathrm{rad} / \mathrm{s}$, for $300 \mathrm{~s}$.

(b) Frequency sweep at $1 \%$ strain, from $628 \mathrm{rad} / \mathrm{s}$ to $0.1 \mathrm{rad} / \mathrm{s}$. When choosing the frequency range of interest, consider the risk of outflow as described in Note 9.

(c) Temperature ramp from the current temperature to $20^{\circ} \mathrm{C}$ lower, at $1 \%$ strain, $1 \mathrm{rad} / \mathrm{s}$ and $5{ }^{\circ} \mathrm{C} / \mathrm{min}$.

(d) Repeat steps 2 and $\mathbf{3}$ until complex modulus G* exceeds $10^{7} \mathrm{~Pa}$.

(e) Temperature ramp from current temperature to $200{ }^{\circ} \mathrm{C}$, at $1 \%$ strain, $1 \mathrm{rad} / \mathrm{s}$ and $5{ }^{\circ} \mathrm{C} / \mathrm{min}$.

(f) Frequency sweep at $1 \%$ strain, from $628 \mathrm{rad} / \mathrm{s}$ to $0.1 \mathrm{rad} / \mathrm{s}$. 


\subsection{Geometry Preparation}

3.3 Start Fabrication

3.3.1 Fused Deposition Modelling
The geometry consisted in a prism of squared base. The CAD model was designed with a commercially available CAD software:

1. Sketch a square of $2 \times 2 \mathrm{~cm}$.

2. Extrude it along the vertical axis for $0.4 \mathrm{~cm}$.

3. Save the file in .STL format.

The techniques of choice used to fabricate scaffolds were fused deposition modelling (FDM), 3D-fiber deposition (3DF), and bioextrusion. As a representative case, the machines used were, respectively, Hyrel 3D 30M, EnvisionTEC V1.0 Bioplotter, and SysEng BioScaffolder. All three machines require some preliminary steps before actively manufacturing. These include assembling the extrusion head ( see Note 10), calibrating the working distance (see Note 11), preparing the code, and loading the material. The devices can be seen in Fig. 3, while Fig. 4 shows a picture of the extrusion heads and the nozzles used. For a quality assessment, check the scaffolds under a light microscope, and adjust the printing parameters according to the specific technique used (temperature, pressure or screw speed or rollers speed, deposition speed) to get the desired quality, and manufacture again (see Note 12 for further information about the choice of the right parameters). Table 1 lists a set of optimized parameters for the materials described here. A summary of all the main features of the three different techniques can be found in Table 3 .

Printing with Hyrel 3D 30M printer (Fig. 3c) is described here as an example of FDM. To manufacture the thermoplastic material necessary for this printer, a step on conversion of the pellets into filament is performed using a twin-screw extruder:

1. Mount the $1.5 \mathrm{~mm}$ die.

2. Set the temperature of the machine to $140{ }^{\circ} \mathrm{C}$ and wait for it to stabilize. See Notes 13-15 for recommendations about the choice of the right temperature for deposition.

3. Start the motor by setting the rpm to 100 .

4. Pour progressively up to $7 \mathrm{~g}$ of material in the hopper and push it with the specific tool.

5. Mix for $5 \mathrm{~min}$, open the bypass valve, and collect the filament extruded through the die on aluminum foil, avoiding the different sections to fuse together.

6. Cut any nonuniform sections of the filament.

7. Store the filament in a vacuum-sealed bag in a dry and dark place.

To perform the scaffold fabrication with the Hyrel AM System, install first the two-roller extruder head (Fig. 4c left) and set the 


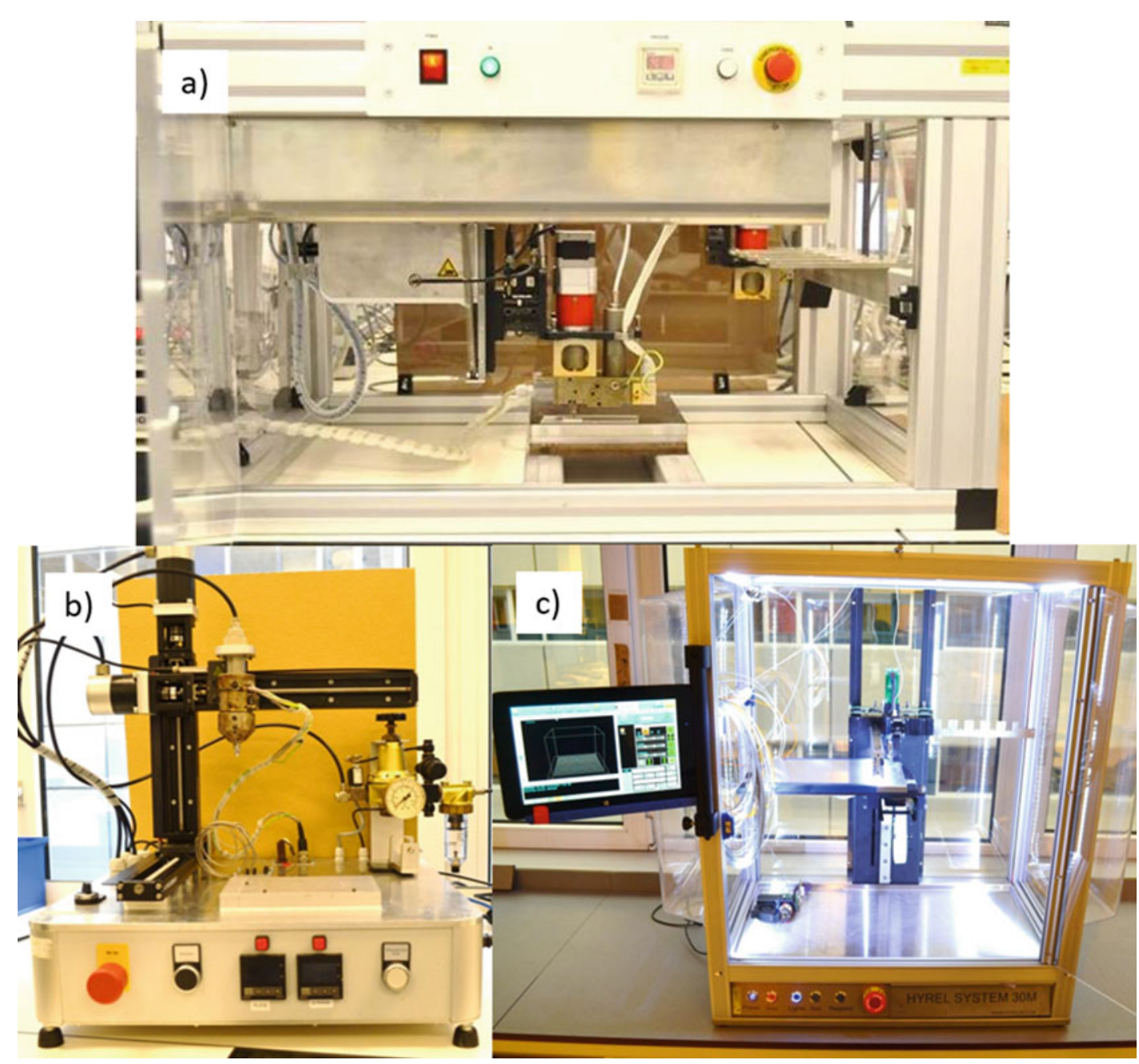

Fig. 3 Examples of the three types of extrusion-based AM systems normally used to produce thermoplasticbased scaffolds: (a) SysEng BioScaffolder with a screw extrusion-based head assisted by pressurized reservoir (bioextrusion example); (b) EnvisionTEC V1.0 Bioplotter, which uses gas pressure-based extrusion (3DF example); and (c) Hyrel 3D printer with a filament-based head (FDM example)

printing height. Lastly, load the filament (brief visual instructions can be found in Supplementary Video 1):

1. Mount the $500 \mu \mathrm{m}$ nozzle (Fig. 4c right) to the extrusion head.

2. Slide the extruder gibs (Fig. 5a) into the head gib slot (Fig. 5b), and make sure the extruder connector is seated properly (Fig. 5c).

3. Tighten the thumbscrew to lock the extruder (Fig. $5 \mathrm{~d}$ ).

4. Stick a stripe of double-sided tape on the building platform (Fig. 5e).

5. Start the controlling software. 


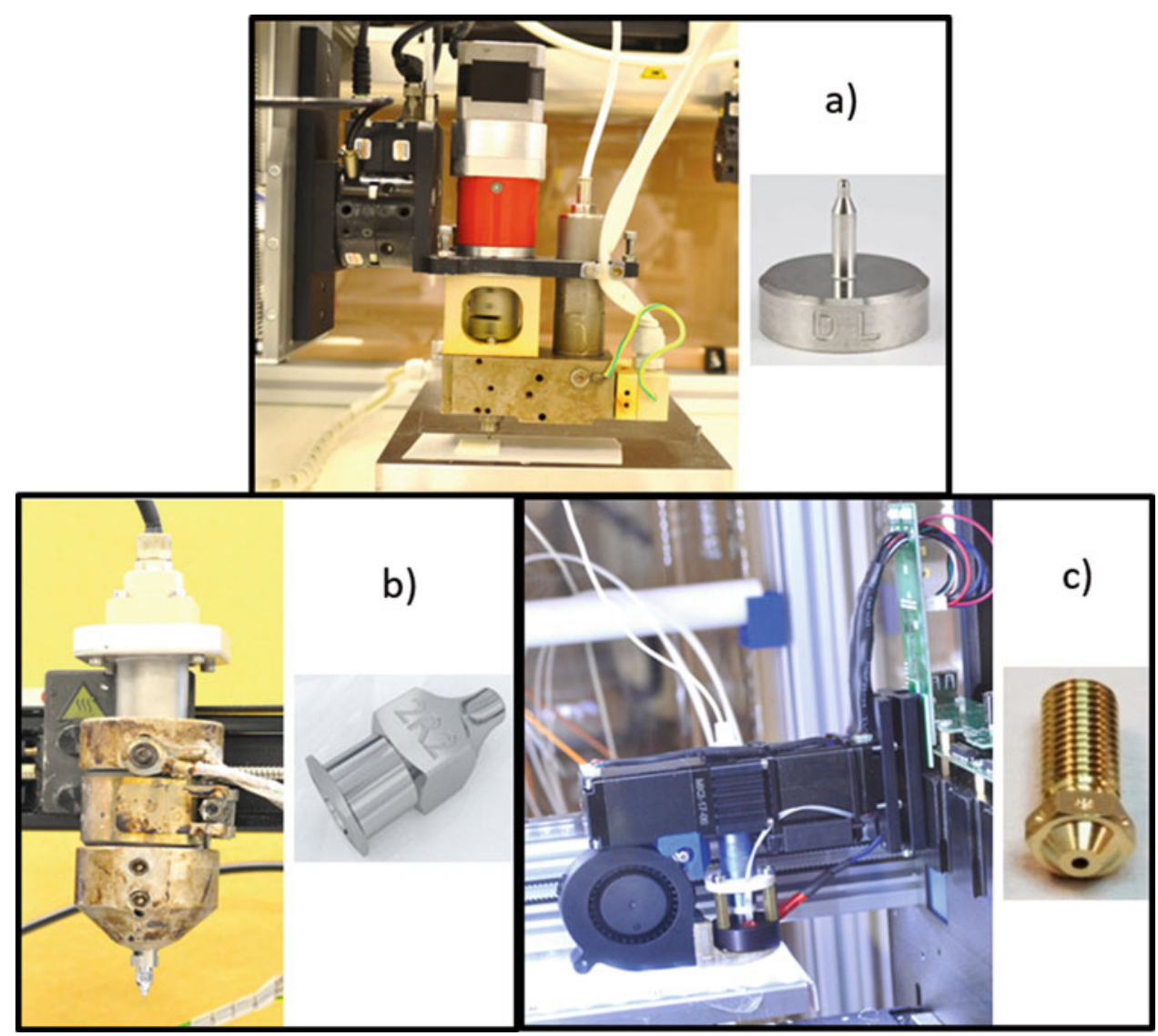

Fig. 4 Detailed view of the extrusion head and the needle/nozzle of the three devices of choice. (a) SysEng BioScaffolder and DL Technology G22 encapsulation needle, (b) EnvisionTEC Bioplotter and stainless steel Luer Lock G21 hypodermic needle, (c) Hyrel 3D and $500 \mu \mathrm{m}$ nozzle

\section{Table 1}

List of the printing parameters used for each technique. Parameters not part of the technique or that could not be programmed are classified as non-applicable (N.A.)

\begin{tabular}{llll}
\hline Parameter & FDM & 3DF & Bioextrusion \\
\hline Needle ID $(\mu \mathrm{m})$ & 500 & 514 & 413 \\
\hline Temperature $\left({ }^{\circ} \mathrm{C}\right)$ & 165 & 195 & 195 \\
\hline $\mathrm{N}_{2}$ Pressure $(\mathrm{bar})$ & N.A. & 5.5 & 4.2 \\
\hline Deposition speed $(\mathrm{mm} / \mathrm{min})$ & 900 & 1000 & 600 \\
\hline Strand distance $(\mathrm{mm})$ & N.A. & 1.75 & 1.5 \\
\hline Infill $(\%)$ & 60 & N.A. & N.A. \\
\hline RPM & N.A. & N.A. & 60 \\
\hline Rollers speed $(\mathrm{RPM})$ & 400 & N.A. & N.A. \\
\hline
\end{tabular}




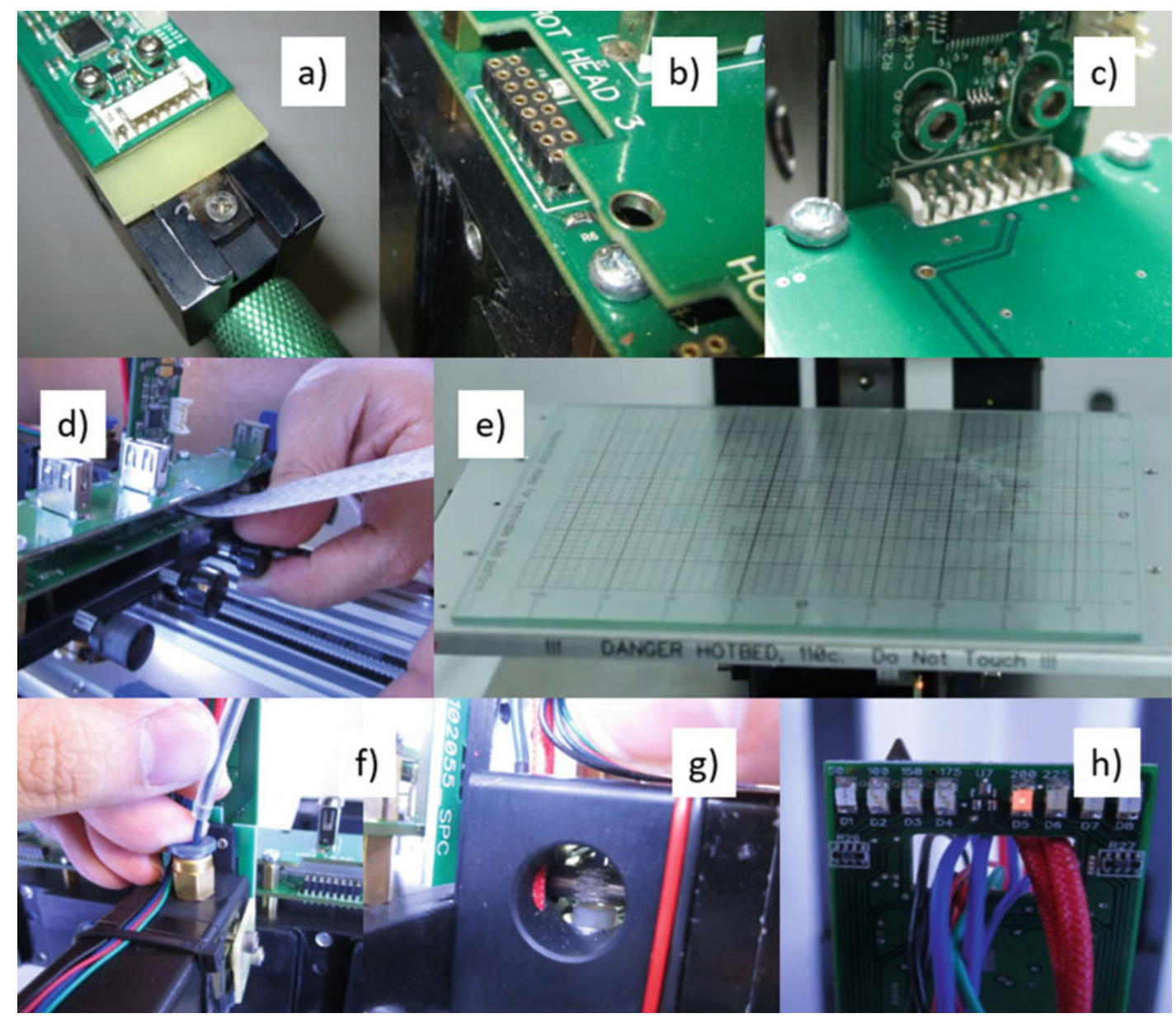

Fig. 5 Detailed view of the components for the head assembling procedure with Hyrel 3D: (a) head gib and connector, (b) socket for the head connector on the printer, (c) proper connection between the head and the printer, (d) tightening of the thumbscrew, (e) detail of the building platform where to apply the double-sided tape, (f) loading of the filament into the blue hose, (g) alignment of the filament with the motor's teeth, (h) rocker switch for filament loading

6. Calibrate the $Z$ axis (Fig. 6): bring the build surface to the nozzle and save as zero height the position where the tape just starts to pinch.

7. Insert the filament in the blue hose (Fig. 5f) and align it with the motor's teeth (Fig. $5 \mathrm{~g}$ ).

8. Activate the rocker switch to load the filament (Fig. 5h) and lock the filament guide tube.

Generate the G-code for the AM system from the previously created STL file via the same controlling software:

1. Import the STL file of the part to be printed.

2. Run the slicing software and set the following parameters: 


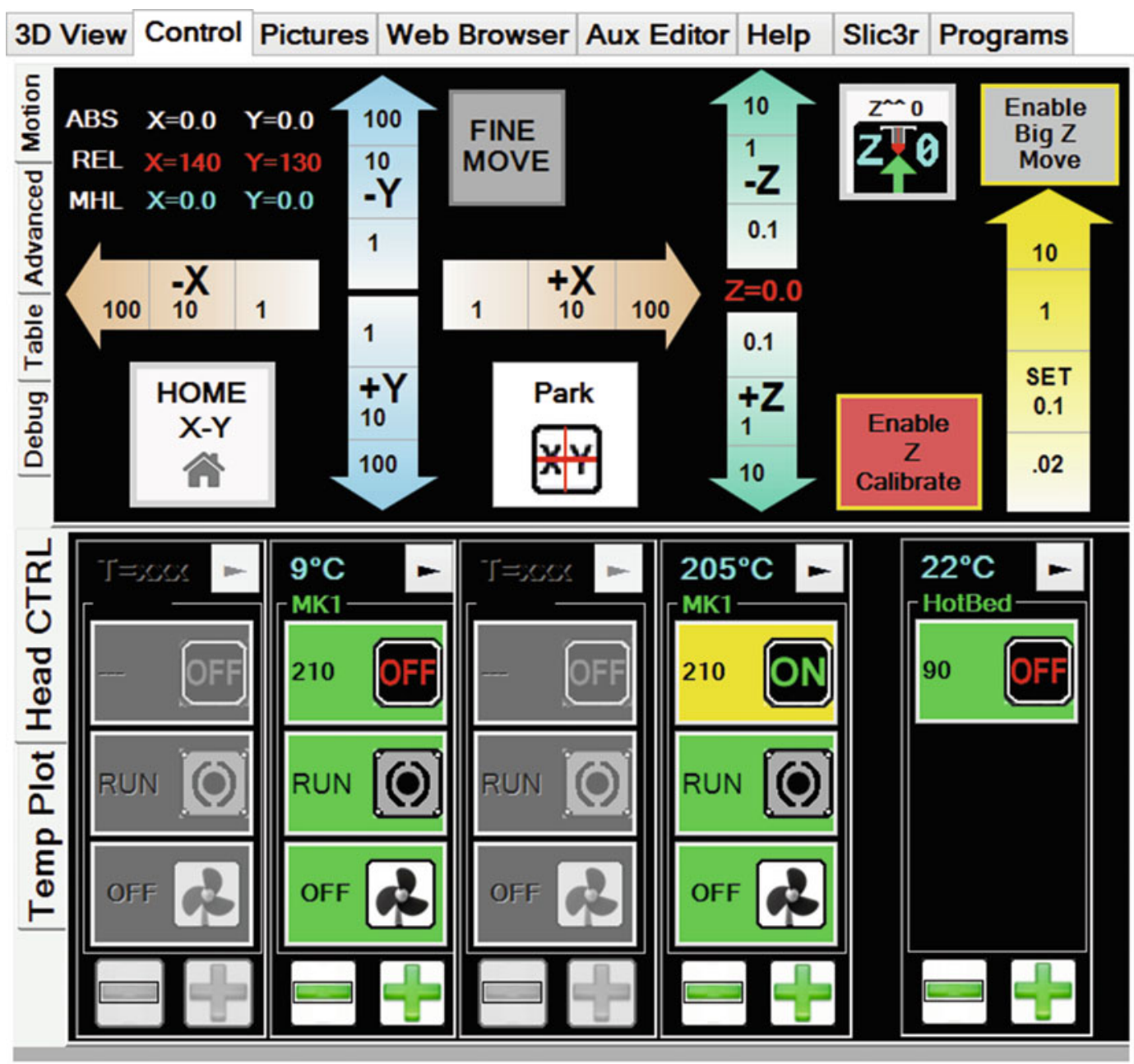

Fig. 6 Control tab of the Repetrel software. In the top part of the window, the commands to move the deposition head can be seen. In the bottom part are the temperature, roller, and fan controllers for each installed head

(a) Layer height: $0.5 \mathrm{~mm}$.

(b) Fill density: 60\%.

(c) Fill angle: $90 \%$.

(d) Infill speed: $15 \mathrm{~mm} / \mathrm{s}$.

(e) Nozzle internal diameter (ID): $0.5 \mathrm{~mm}$.

(f) See Note 17 for further parameters to be specified.

3. Export the G-code and import it in the controlling software.

By using the same software, the deposition process can now be started:

1. Set the print head temperature to $165{ }^{\circ} \mathrm{C}$ and wait for the extruder to heat up. 
3.3.2 3D-Fiber

Deposition
2. Set the rollers speed to $400 \mathrm{rpm}$ and purge some material until the flow is consistent and smooth.

3. Remove any filament dribble from the extruder nozzle.

4. Start the printing.

5. Pay close attention to the first layers as they are those determining the stability of the printout during the process.

6. At the end of the process, let the scaffolds to cool down and then pour some ethanol at its base.

7. After some time (typically in the order of a couple of minutes), the part can be detached.

8. Dry the scaffold with nitrogen and store vacuum-sealed in a dark and dry place.

Manufacturing with a Bioplotter V1.0 (EnvisionTEC, Fig. 3b) is described as an example of the $3 \mathrm{DF}$ process, using a stainless steel Luer lock G21 hypodermic needle (Fig. 4b right) shortened to a length of approximately $15 \mathrm{~mm}$ (measured from the beginning of the Luer lock mechanism). The machine works by heating the polymer pellets in a cartridge until the melting point. Then, the polymer melt can be extruded via the needle by the application of a gas pressure. Normally an inert and dry gas (e.g., nitrogen) is used to minimize polymer degradation.

The fabrication process was prepared as follows (brief visual instructions can be found in Supplementary Video 2):

1. Fix the needle on the cartridge (parts shown in Fig. 7a).

2. Slide the stainless steel cartridge inside the heater block (Fig. 7b) and fix it in position.

3. Load the material pellets.

4. Lock the pressure valve (Fig. 7c) onto the cartridge.

5. Start the slicing software.

6. Create a new material dataset with the following parameters (as shown in Fig. 8):

(a) Feed XY: $1000 \mathrm{~mm} / \mathrm{min}$.

(b) Layer thickness: $0.4 \mathrm{~mm}$.

(c) Pattern: $90^{\circ}$.

(d) Strand distance: $1.75 \mathrm{~mm}$.

(e) Check "Meander."

(f) See Note 17 for further parameters to be specified.

7. Load the .STL file and select the material dataset just created for all the layers.

8. Generate the .NC-code and save it. 


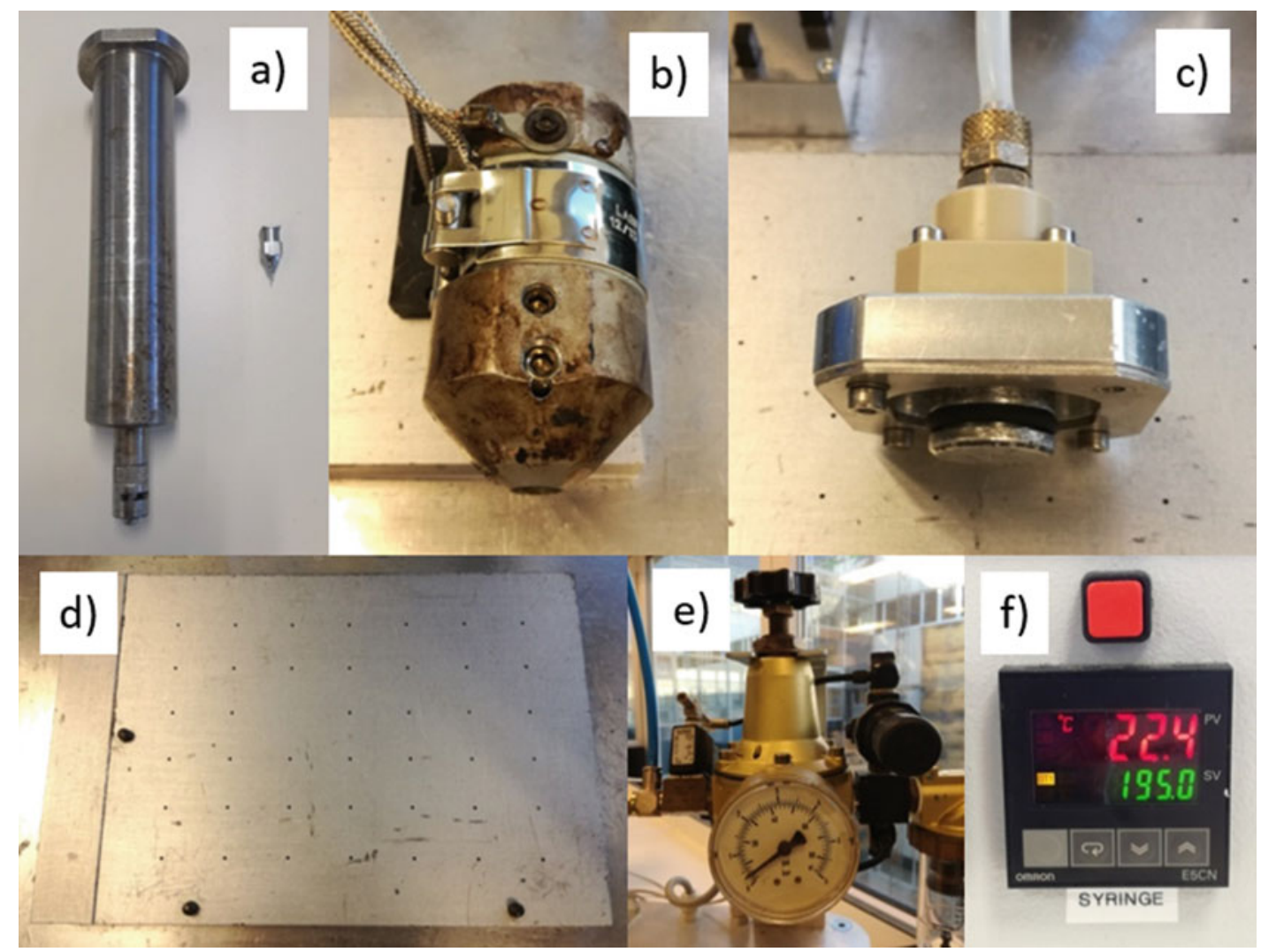

Fig. 7 Detailed view of the components for the head assembling procedure with EnvisionTEC Bioplotter: (a) cartridge and needle, (b) heater block, (c) pressure valve, (d) building platform, (e) nitrogen line regulator, (f) temperature controller

9. Launch the machine controlling software (a detailed view can be seen in Fig. 9) and load the code.

10. Stick a stripe of double-sided tape on the building platform (Fig. 7d).

11. Calibrate the $Z$ axis by moving the print head to the desired printing origin and set this as zero in the software.

12. Adjust the pressure on the compressed nitrogen line regulator (Fig. 7e) to 5.5 bars.

13. Set the temperature to $195{ }^{\circ} \mathrm{C}$ on the temperature controller (Fig. 7f) and wait for the cartridge to heat up. See Notes 13-16 for recommendations about the choice of the right temperature for deposition.

14. Purge material until the flow is consistent and smooth.

15. Remove any filament debris from the extruder needle.

16. Press Start on the controlling software to initiate printing.

17. Pay close attention to the first layers as they are those determining the stability of the printout during the process. 


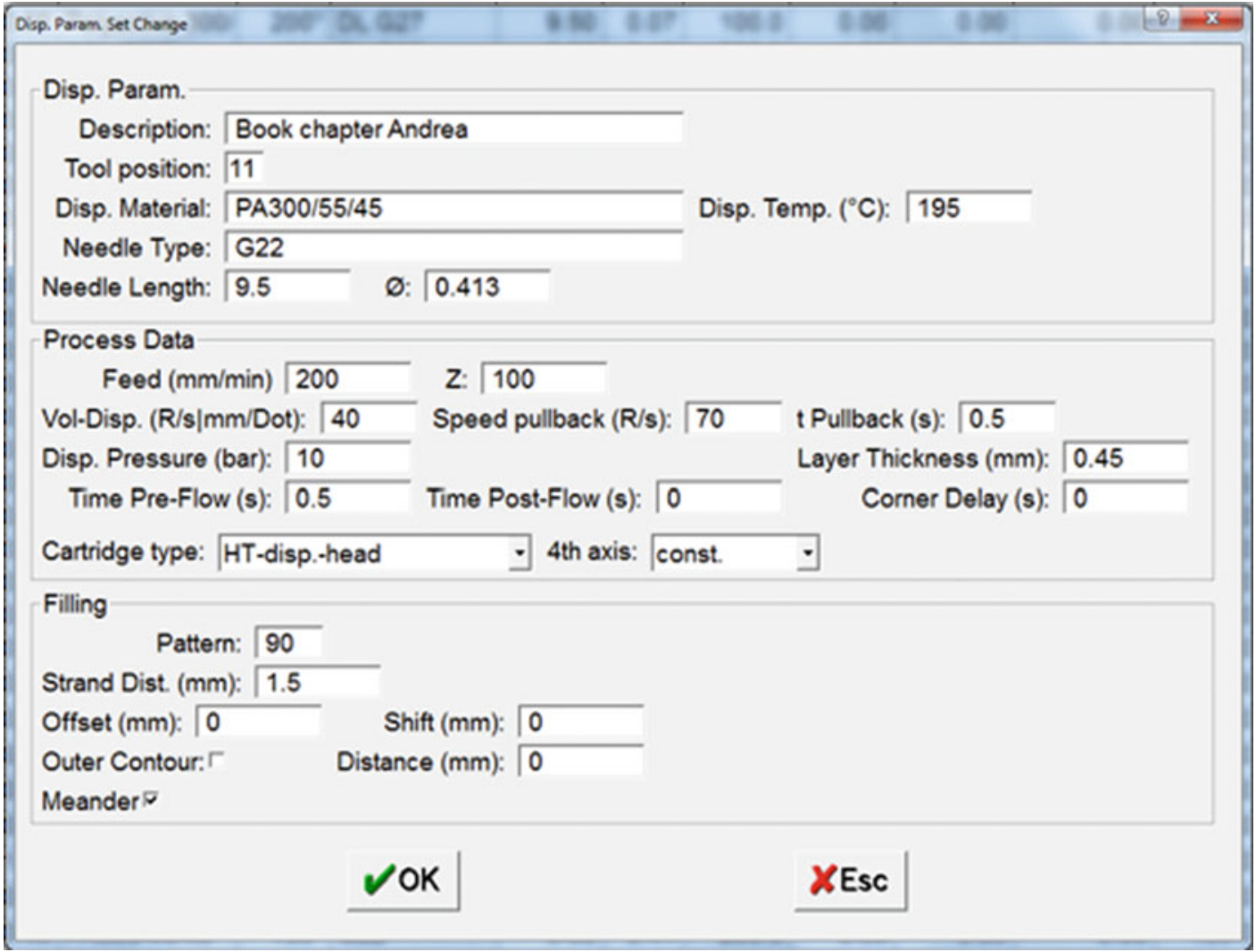

Fig. 8 New dataset window of the PrimCAM slicing software to create a new dataset of fabrication parameters

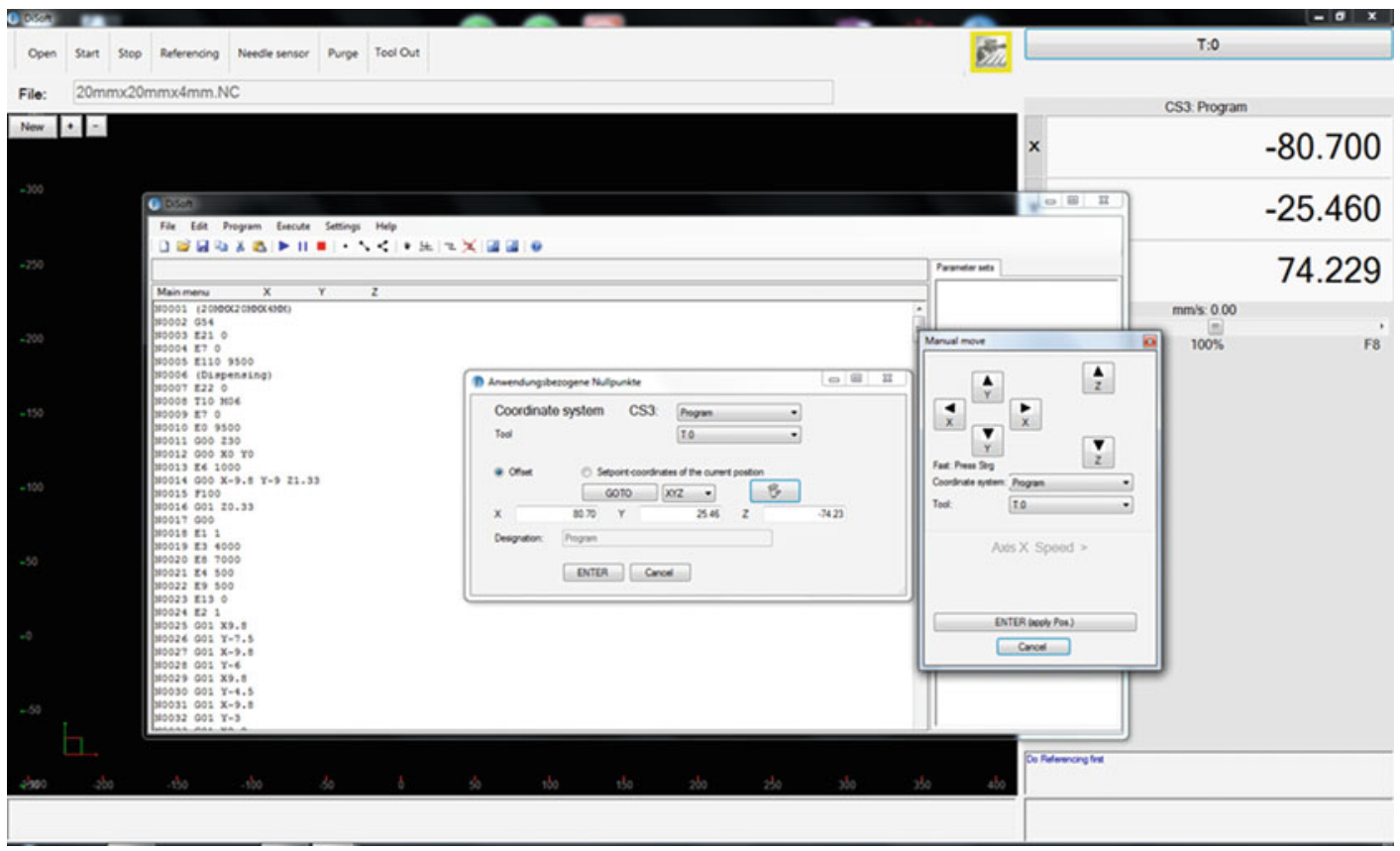

Fig. 9 Details of the DiSoft controlling software. In particular, the window with the NC-code and the head positioning commands can be seen 
18. At the end of the process, let the part cool down and then pour some ethanol at its base.

19. After some time (i.e., a couple of minutes), the part can be detached.

20. Dry the scaffold with nitrogen and store vacuum-sealed in a dark and dry place.

Manufacturing with a SysEng BioScaffolder (Fig. 3a) equipped with a G22 encapsulation needle (Fig. 4a right) is described as an example of a screw-based AM system. The following steps need to be followed for preparation of the system (brief visual instructions can be found in Supplementary Video 3):

1. Assemble the extrusion head (result of the assembling shown in Fig. 10a).
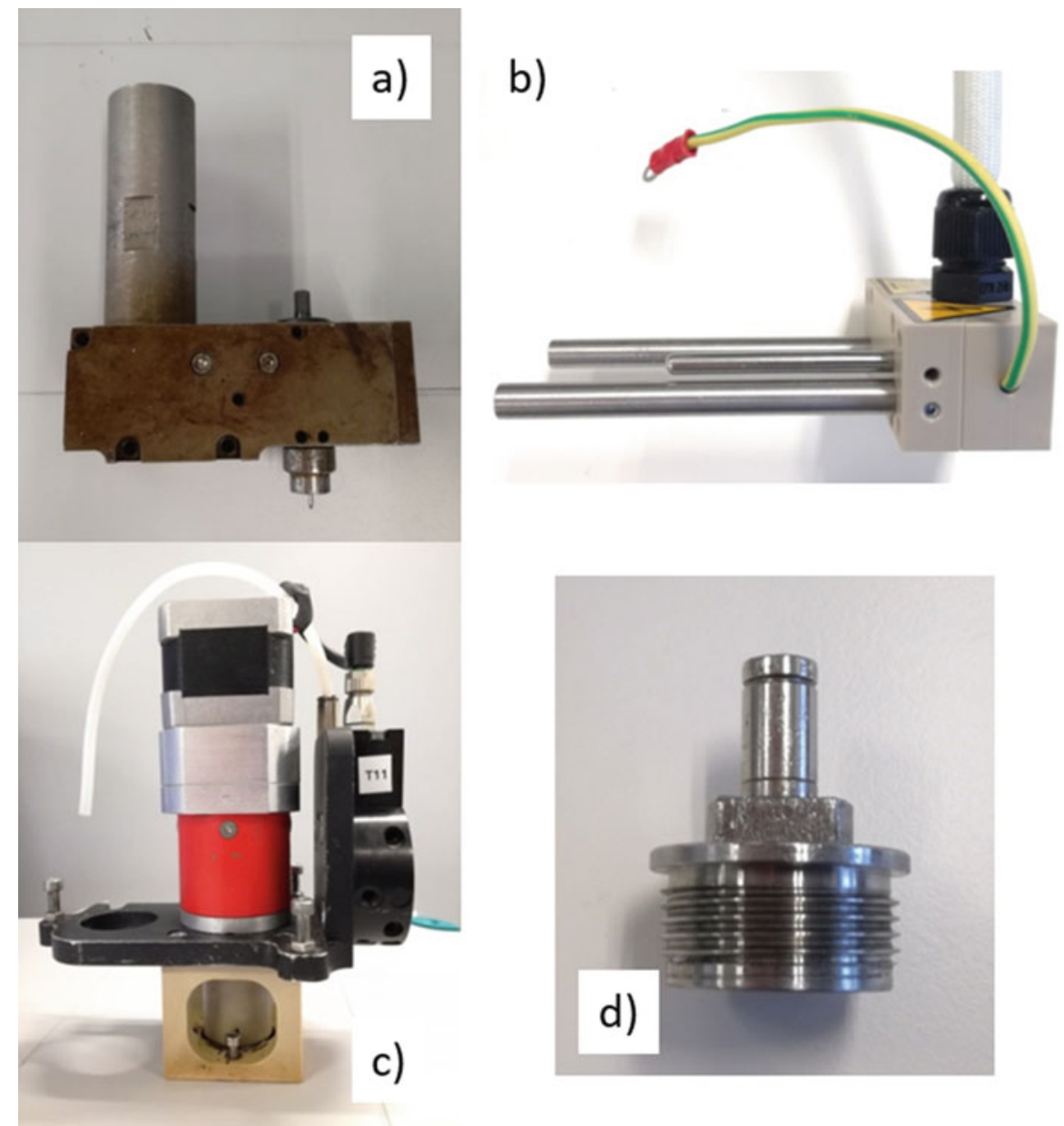

Fig. 10 Detailed view of the components for the head assembling procedure with SysEng BioScaffolder: (a) the print head and the reservoir, (b) the heating element, (c) the motor assembly, (d) the nitrogen pressure valve 
2. Connect the heater (shown in Fig. 10b) and the motor (Fig. 10c).

3. Load the material and close the reservoir with the nitrogen valve (Fig. 10d).

4. Mount the extrusion head in place and turn the machine on.

5. Start the slicing software.

6. Create a new material dataset with the following parameters:

(a) Feed XY: $200 \mathrm{~mm} / \mathrm{min}$.

(b) Vol-Disp. (rpm): 100.

(c) Disp. pressure: 10 bar.

(d) Layer thickness: $0.21 \mathrm{~mm}$.

(e) Pattern: $90^{\circ}$.

(f) Strand distance: $1 \mathrm{~mm}$.

(g) Check "Meander."

(h) See Note 17 for further parameters to be specified.

7. Load the .STL file and select the material dataset just created for all the layers.

8. Generate the .NC-code and save it.

9. Launch the machine controlling software (Fig. 9) and load the . NC-code.

10. Stick a stripe of double-sided tape on the building platform.

11. Set the zero point by moving the extrusion head to the desired manufacturing origin.

12. Set the temperature to $195{ }^{\circ} \mathrm{C}$ on the temperature controller and wait for the cartridge to heat up. See Notes 13-16 for recommendations about the choice of the right temperature for deposition.

13. After the cartridge has reached the setpoint, allow the polymer to properly melt for around 15-20 $\mathrm{min}$.

14. In the machine controlling software, click the purge button until the flow is consistent and smooth.

15. Remove any filament debris from the extruder needle.

16. Press Start on the controlling software.

17. Pay close attention to the first layers as they are those determining the stability of the printout during the process.

18. At the end of the process, let the part cool down and then pour some ethanol at its base.

19. After some time (i.e., a couple of minutes), the part can be detached.

20. Dry the scaffold with nitrogen and store it vacuum-sealed in a dark and dry place. 


\subsection{SEM Analysis}

To analyze the scaffold under scanning electron microscope, the steps below should be followed (described here for a Philips XL30 SEM):

1. Soak the scaffold in liquid nitrogen for $5 \mathrm{~min}$.

2. Cut the scaffold with a razor blade along the vertical axis.

3. Apply a carbon conductive tape to the sample holders, and stick the samples on them with the section of interest facing upward.

4. Load the scaffolds on the rotating platform inside the gold coating chamber of the sputter coating apparatus in use. Check Note 18 for the importance of a proper coating.

5 . Turn on the machine and apply vacuum.

6. Flush four times with argon.

7. Sputter coat with gold for $100 \mathrm{~s}$.

The samples are then ready to be loaded in the SEM and imaged:

1. Vent the chamber and open it.

2. Load the sample holders onto the platform and close the chamber.

3. Apply vacuum. Follow the recommendation in Note 19 for proper imaging.

4. Switch on the electron beam and set it at $10 \mathrm{kV}$.

5. Focus at a low magnification and then go to the desired magnification and focus again. Adjust stigmatism if required.

6. Set the working distance at the characteristic value for the microscope in use and adjust the focus again. Repeat this step until the actual working distance value is as close as possible to the characteristic one.

7. Image the cross section of the scaffolds to have a clear view of the filament diameter and of the lateral porosity. To avoid damages to the scaffold, see Note 20.

8. Measure the filaments diameter, the filament distance, and the layer thickness in the SEM image to characterize the scaffold.

\section{Notes}

1. To avoid unreliable data during DSC measurements and that the pan sticks in the machine, ensure that the scale, the tweezers, the pans, and the lids are clean.

2. The sample should be cut so that to avoid irregularities in shape. If the contact area between the sample and the pan is sufficiently uniform, the heat transmission will be regular. 


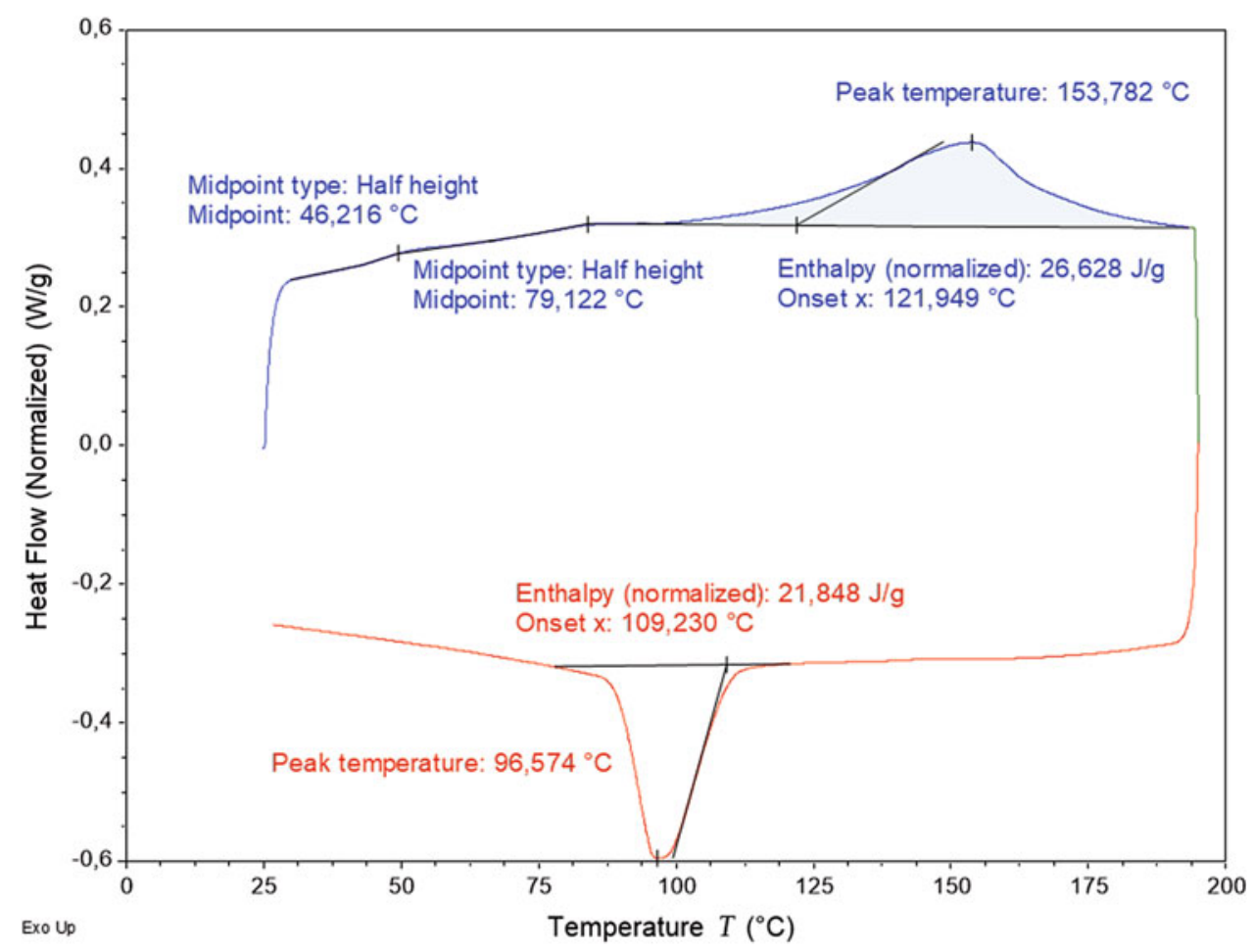

Fig. 11 DSC thermogram of 300PEOT55PBT45 measured at a heating/cooling rate of $10{ }^{\circ} \mathrm{C} / \mathrm{min}$ under nitrogen atmosphere. Positive heat flow corresponds to endothermic processes taking place in the sample. The blue line (heating cycle) shows two glass transitions (typical for such a diblock copolymer) and one melting peak. During cooling (red line), the material crystallized and reached a crystalline content nearly as high as in its initial state (as can be seen when comparing the enthalpy values)

Consequently, the baseline will be flat and with no sudden steps. For example, a good smooth scan is demonstrated in Fig. 11.

3. In case of comparative studies, ensure equal sample weights to minimize heat transfer effects and consequential thermal lags.

4. To avoid material degradation during the measurement, the final temperature of the heating cycle should not be too high (about $50{ }^{\circ} \mathrm{C}$ above the expected peak melting temperature), and the isothermal time should be limited. If the melting temperature is ambiguous, perform thermogravimetric analysis (TGA) first to identify the onset of thermal degradation, which negatively affects an adequate DSC measurement.

5. To eliminate the effect of thermal history, i.e., processing routes, on the melting temperature $\left(T_{\mathrm{m}}\right)$, it might be necessary to reheat the sample in a second ramp to the maximum temperature $\left(T_{\mathrm{m}}+30^{\circ} \mathrm{C}\right)$. The melting temperature thus obtained is intrinsic to the material of interest. 
6. To avoid unnecessary additional thermal stress on the sample during rheometry, perform sample loading as fast as possible. In case of thermally unstable materials, one can also pre-shape a disc via compression molding or preferred solution casting excluding any negative thermal effects prior to measurement.

7. Before setting the measurement gap, wait for the temperature to stabilize. During reheating after trimming, the sample viscosity could drop again, and material flow out of the plate might take place.

8. If the measuring gap is too big and the sample exhibits low viscosity, there might be outflow of material resulting in a sudden drop in viscosity. When in a melt state, regular temperature ramps should show a regular increasing trend of complex viscosity with decreasing temperature, as shown in Fig. 12.

9. Outflow could take place also when running frequency sweeps on a low-viscosity samples at very low and very high frequencies. This is due, respectively, to a stronger viscous component and to inertia. If the chosen frequency range is appropriate, the (viscosity vs. frequency) curves should be flat when on the Newtonian plateau and gradually decreasing at higher rates, as can be seen in Fig. 13 .

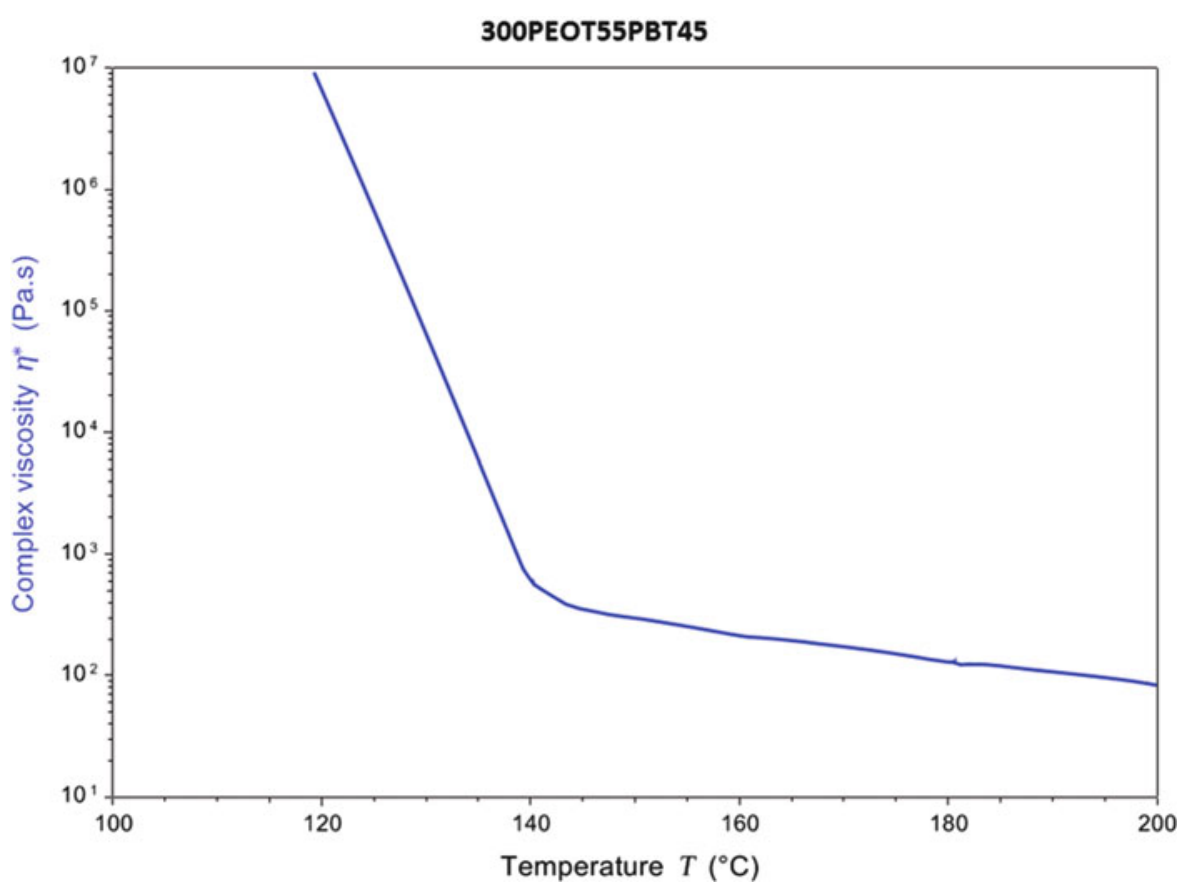

Fig. 12 Temperature dependence of complex viscosity of 300PEOT55PBT45, measured at $1 \%$ of applied strain and $1 \mathrm{rad} / \mathrm{s}$, in cooling. The sudden increase in viscosity at around $140{ }^{\circ} \mathrm{C}$ is due to the onset of the crystallization process, highly dependent on the cooling 


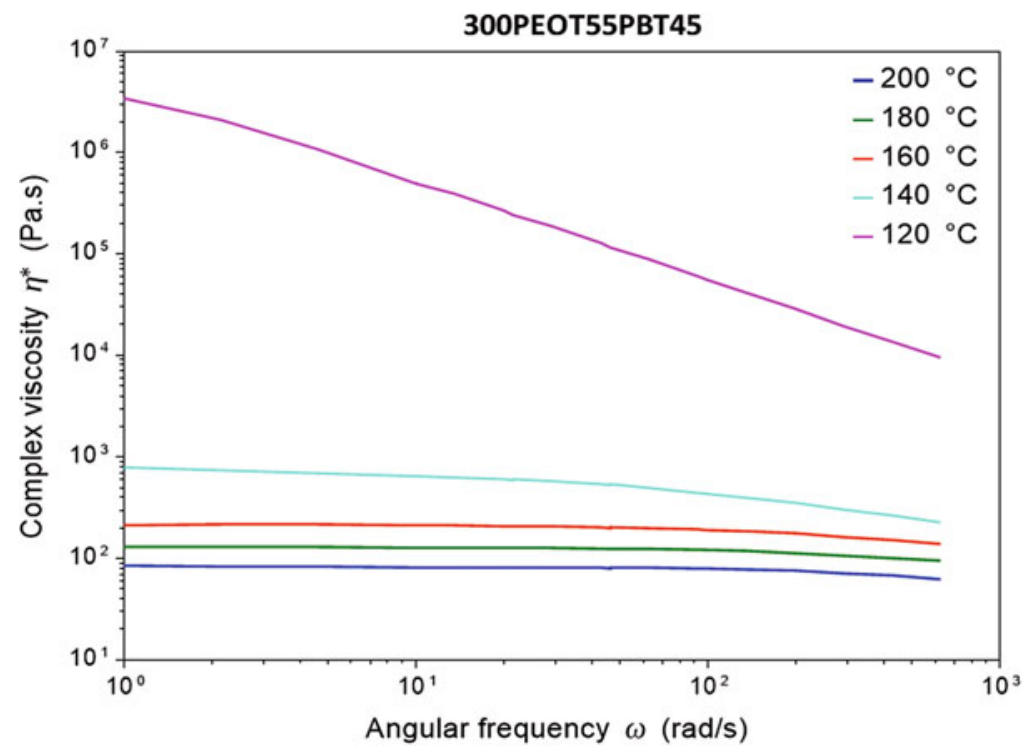

Fig. 13 Frequency dependence of complex viscosity of 300PET55PBT45 at decreasing temperatures, measured at $1 \%$ applied strain. It can be seen that the Newtonian plateau shifts to lower frequencies with decreasing temperature. In particular, the crystallization is already complete at $120^{\circ} \mathrm{C}$ and the Newtonian plateau cannot be seen

10. Tighten the screws during the assembly of the extrusion heads to avoid polymer leakages, but not too strongly in order to avoid mechanical damage.

11. When setting the origin of the vertical axis, move the print head slowly to avoid crashing the needle against the printing stage.

12. Getting the desired scaffold morphology is the result of a balance between temperature, extrusion driving forces (rollers speed, pressure, and the combination of pressure/screw speed for FDM, 3DF, and bioextrusion, respectively), and deposition speed. These parameters are material and machine dependent. The right parameters to obtain the desired morphology need to be determined experimentally through a feedback loop of fabrication and microscopy analysis. In Fig. 14, it is possible to see the parts fabricated with the set of parameters that led to fiber thicknesses as close as possible to the nozzle internal diameters, as later confirmed by SEM analysis.

13. The higher the temperature and the driving forces, the higher the flow rate. This means that more material is deposited per length, practically resulting in thicker fibers and sagging. As a result, the lateral porosity may be compromised. To avoid this scenario, the deposition speed should be increased accordingly. Examples of properly printed scaffolds and their average fiber 


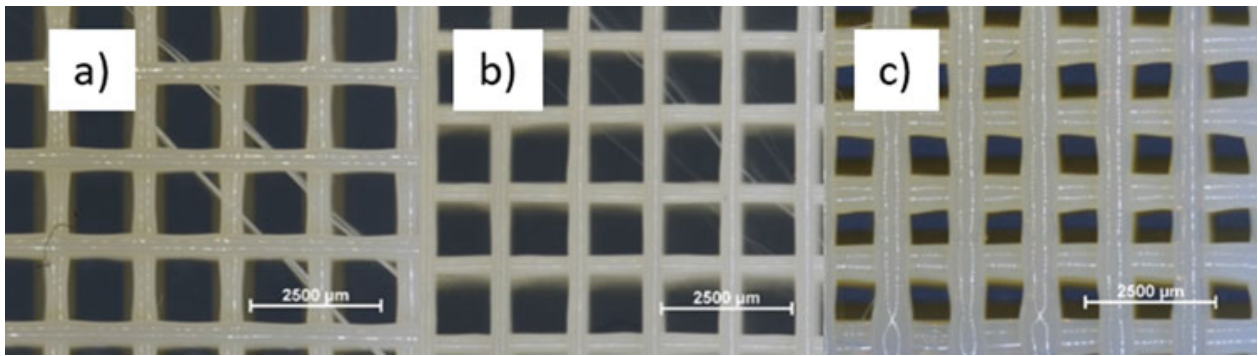

Fig. 14 Stereomicroscope images of scaffolds fabricated with the final set of parameters for Bioplotter (a), BioScaffolder (b), and Hyrel 3D (c). The morphology looks regular with no surface defects and quick measurements confirmed that the fiber diameters are close to the desired ones. Additionally, some free thin filaments can be seen in the background of images (a and $\mathbf{b}$ ). These sometimes form as the printing nozzle finishes the deposition of one filament and moves to the next point as explained later

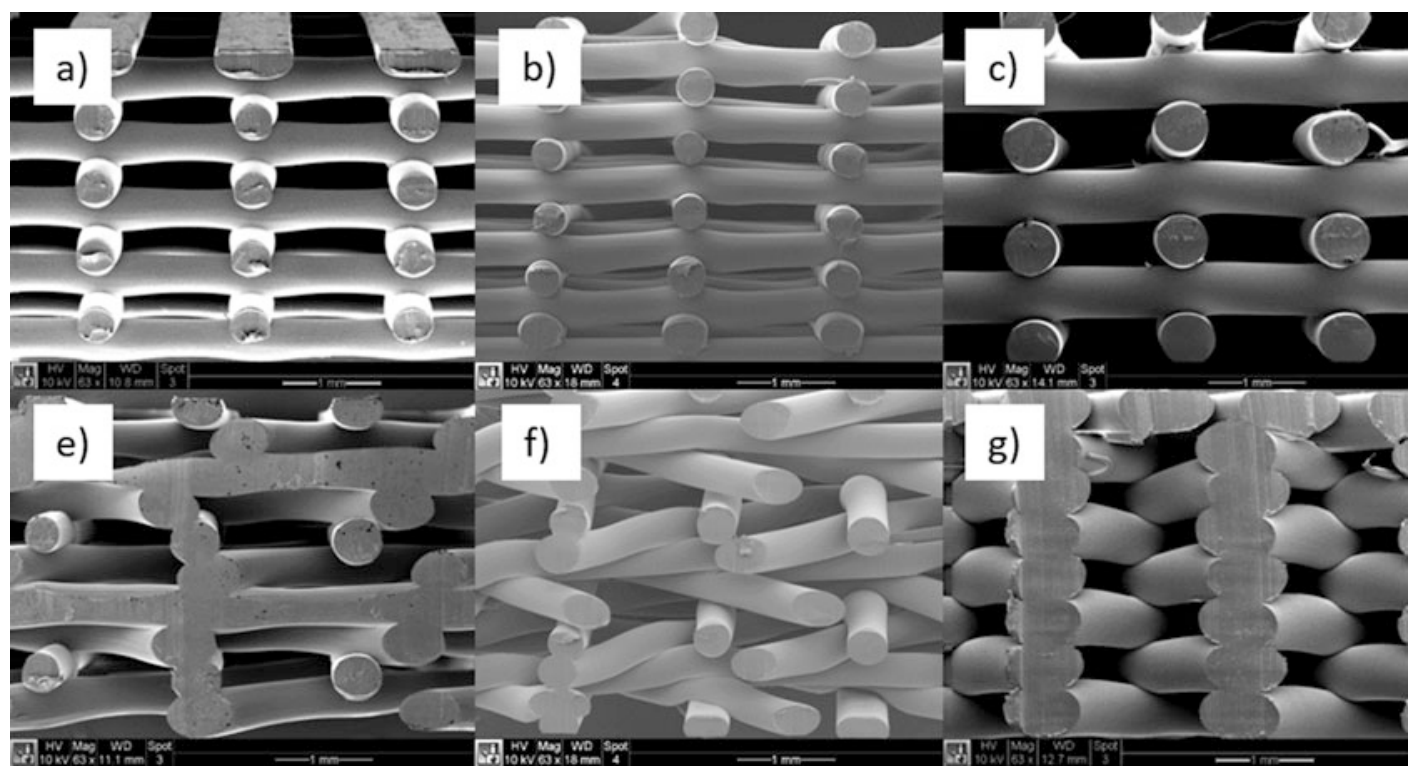

Fig. 15 SEM images of scaffolds fabricated with Bioplotter (a, e), BioScaffolder (b, f), and Hyrel 3D (c, g), following a 0-90 pattern $(\mathbf{a}, \mathbf{b}, \mathbf{c}), 0-45(\mathbf{e}, \mathbf{f})$, and 45-45 (g). The pictures clearly show a regular structure with open lateral pores and no sagging

dimensions are shown in Fig. 15 and Table 2, respectively. In Fig. 16 the result of slow printing speed can be seen instead.

14. Conversely, by reducing the temperature or the driving forces, the flow rate decreases. This could lead to thinner fibers or, in extreme cases, to broken fibers, but also to limited interaction between filaments of subsequent layers. This last effect is due to the shorter time needed for the filament to solidify and to interact with the previous layer.

15. The DSC measurements are needed to evaluate the temperature range when an unknown material is in the melt state and 
Table 2

Measured filament thickness (9 measurements) with SEM and comparison with nominal nozzle internal diameter

\begin{tabular}{llll}
\hline Dimensions $(\mu \mathrm{m})$ & FDM & 3DF & Bioextrusion \\
\hline Nozzle & 500 & 514 & 413 \\
Filament & $505 \pm 18$ & $523 \pm 19$ & $401 \pm 35$ \\
\hline
\end{tabular}

The chosen set of parameters for each technique allowed to reach dimensions close to the programmed ones

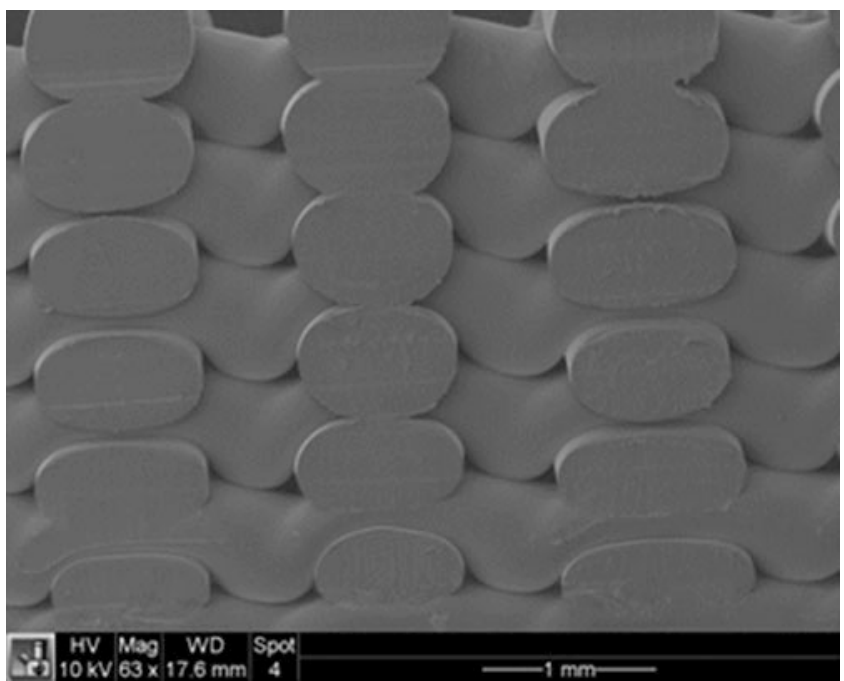

Fig. 16 Detail of a scaffold fabricated with a deposition speed too low with respect to the set flow rate. No lateral porosity can be seen and the cross section of the filaments is highly elliptical

therefore suitable for processing. Depending on the apparatus, semicrystalline thermoplastics are usually processed at temperatures from 10 to $30{ }^{\circ} \mathrm{C}$ higher than the melting point. In case of amorphous grades, rheological measurements are needed to give further insights about the material processing window. Rheometry is used to evaluate the material viscosity and therefore how it flows at different temperatures. Increasing the temperature promotes flow but increases the solidification time after deposition, which could cause loss of geometrical accuracy. By reducing the temperature, the risk of degradation decreases, but higher driving forces for deposition are needed.

16. With 3D-fiber deposition and bioextrusion, the duration of the fabrication session should be limited as the material in the reservoir might thermally degrade over time. Lowering the temperature can be an option, but this would influence the flow as well. 


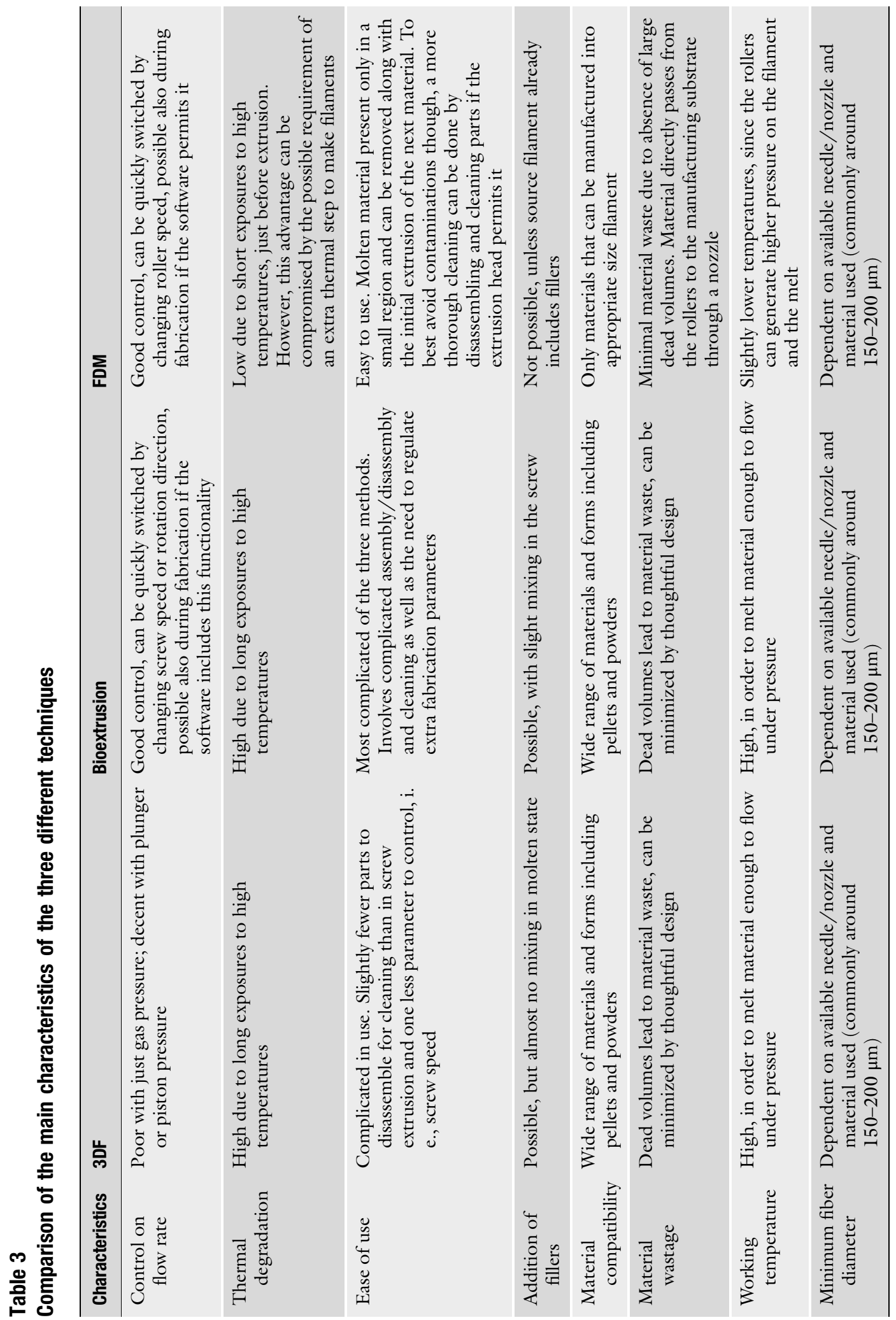




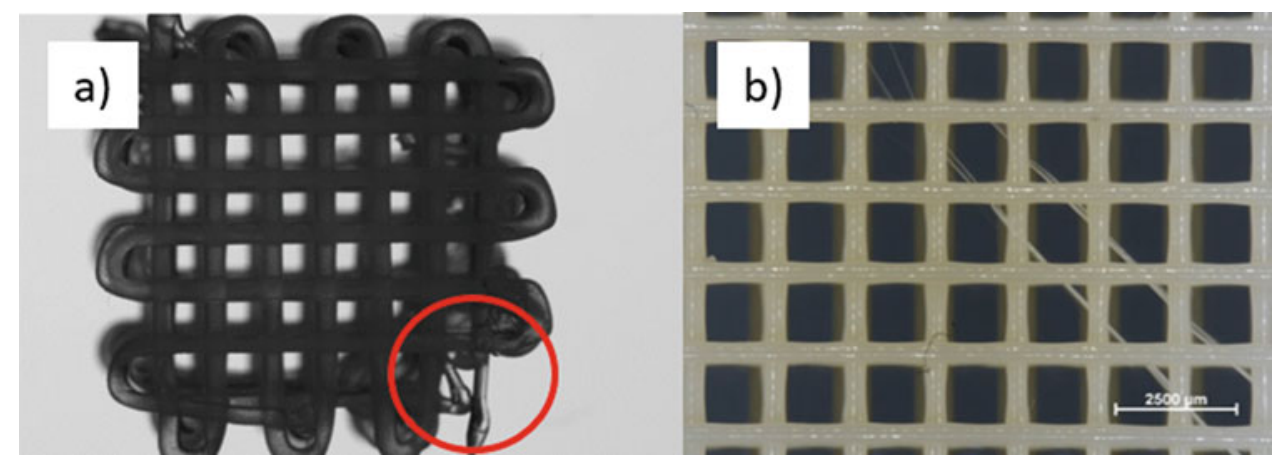

Fig. 17 Examples of defects due to late flow response of the material (a) and excessive flow at the end of the deposition (b). The red circle in (a) highlights an empty spot where the polymer was not deposited because of delayed flow. In (b), thin filaments resulting from the viscoelasticity of the material can be seen. As shown previously, when the nozzle finishes depositing one filament and moves to the next deposition point, some thin polymeric strands could form. This is the result of the viscoelastic nature of polymers, where cohesive forces within the material prevent the fiber from being terminated when the flow is stopped

17. As a consequence of the viscoelastic nature of polymers, it might be necessary to set a pre-flow time or pullback to avoid further fabrication defects. If the response of the polymer is delayed when the printer starts to extrude, some voids might be present in the scaffold. This can be clearly seen in Fig. 17a, where the bottom right corner of the scaffold (where the deposition of each layer started from) is missing. A possible solution is to set a proper pre-flow time. Conversely, if the polymer keeps slightly flowing from the needle even after the end of the deposition, thin undesired filament will be present all over the scaffold. The pullback (only available in bioextrusion) allows applying a backpressure to stop the flow. This defect is shown in Fig. 17b.

18. Be sure to properly sputter coat the sample. As polymers are not highly conductive, uneven or missing coating might affect the quality of the images due to charge accumulation from the incoming electron beam. This can be ensured, for example, by checking that the samples can rotate freely on the rotating platform without interfering with each other. Improper flushing and too short coating time might affect the quality of the coating as well.

19. The SEM analysis should be started only after the chamber is under vacuum or the electron beam might be disturbed by the particles in the atmosphere.

20. Do not keep the beam focused on the same spot for a long time in order to avoid heating from the highly focused electron beam energy. 


\section{References}

1. Lee JM, Yeong WY (2015) A preliminary model of time-pressure dispensing system for bioprinting based on printing and material parameters. Virtual Phys Prototyp 10:3-8

2. Mota C, Puppi D, Chiellini F, Chiellini E (2015) Additive manufacturing techniques for the production of tissue engineering constructs. J Tissue Eng Regen Med 9:174-190

3. Li MG, Tian XY, Chen XB (2009) A brief review of dispensing-based rapid prototyping techniques in tissue scaffold fabrication: role of modeling on scaffold properties prediction. Biofab 1:32001

4. Chia HN, Wu BM (2015) Recent advances in 3D printing of biomaterials. J Biol Eng 9:4

5. Moroni L, Boland T, Burdick JA, De Maria C, Derby B, Yoo JJ, Vozzi G (2017) Biofabrication: a guide to technology and terminology. Trends Biotechnol. https://doi.org/10. 1016/j.tibtech.2017.10.015

6. Taboas JM, Maddox RD, Krebsbach PH, Hollister SJ (2003) Indirect solid free form fabrication of local and global porous, biomimetic and composite 3D polymer-ceramic scaffolds. Biomaterials 24:181-194

7. Youssef A, Hollister SJ, Dalton PD, Amin R, Knowlton S, Hart A (2017) Current and emerging applications of $3 \mathrm{D}$ printing in medicine. Biofabrication 9:1-9

8. Poh PSP, Chhaya MP, Wunner FM, De-JuanPardo EM, Schilling AF, Schantz JT, van Griensven M, Hutmacher DW (2016) Polylactides in additive biomanufacturing. Adv Drug Deliv Rev 107:228-246

9. Malda J, Visser J, Melchels FP, Jüngst T, Hennink WE, Dhert WJA, Groll J, Hutmacher DW
(2013) 25th anniversary article: Engineering hydrogels for biofabrication. Adv Mater 25:5011-5028

10. Moroni L, de Wijn JR, van Blitterswijk CA (2006) 3D fiber-deposited scaffolds for tissue engineering: influence of pores geometry and architecture on dynamic mechanical properties. Biomaterials 27:974-985

11. Hendriks JAA, Moroni L, Riesle J, de Wijn JR, van Blitterswijk CA (2013) The effect of scaffold-cell entrapment capacity and physicochemical properties on cartilage regeneration. Biomaterials 34:4259-4265

12. Nandakumar A, Cruz C, Mentink A, Tahmasebi Birgani Z, Moroni L, Van Blitterswijk C, Habibovic P (2013) Monolithic and assembled polymer-ceramic composites for bone regeneration. Acta Biomater 9:5708-5717

13. Korpela J, Kokkari A, Korhonen H, Malin M, Narhi T, Seppalea J (2013) Biodegradable and bioactive porous scaffold structures prepared using fused deposition modeling. J Biomed Mater Res Part B Appl Biomater 101:610-619

14. Marchioli G, Di Luca A, de Koning E, Engelse M, Van Blitterswijk CA, Karperien M, Van Apeldoorn AA, Moroni L (2016) Hybrid polycaprolactone/alginate scaffolds functionalized with VEGF to promote de novo vessel formation for the transplantation of islets of langerhans. Adv Healthc Mater 5:1606-1616

15. Di Luca A, Longoni A, Criscenti G, Mota C, van Blitterswijk C, Moroni L (2016) Toward mimicking the bone structure: design of novel hierarchical scaffolds with a tailored radial porosity gradient. Biofabrication 8:45007 